\title{
Estado, ilegalidad y orden social en perspectiva comparativa: una aproximación mediante estudios de caso*
}

DOI: https://doi.org/10.18046/recs.i32.3987

\author{
State, Illegality, and Social Order from a Comparative \\ Perspective: A Case Study Approach

\section{Daniel Míguez ${ }^{* *}$} \\ Universidad Nacional del Centro de la Provincia de Buenos Aires (Tandil, Argentina)
}

\footnotetext{
*Este artículo es resultado de la investigación "Violencia, Sociabilidad y Cultura Política en Conglomerados Urbanos", financiada por un subsidio de la Agencia Nacional de Investigaciones Científicas y Técnicas (PICT 99/Nro. 4-6699). Artículo recibido el 21.04.2020 y aceptado el 23.10.2020.

** Correo electrónico: dpmiguez@fch.unicen.edu.ar ORCID: https://orcid.org/oooo-ooo1-7366-0219
} 


\section{Cómo citar/How to cite}

Míguez, Daniel. Estado, ilegalidad y orden social en perspectiva comparativa: una aproximación mediante estudios de caso. Revista CS, 32, 15-41. https://doi.org/10.18046/recs.i32.3987 


\section{Resumen}

El artículo propone algunas reflexiones sobre la relación entre legalidad e ilegalidad en la conformación del orden social, a partir de tres nudos problemáticos. Primero, el hecho de que la mayor parte de los estudios se centra en regiones del planeta donde el Estado centralizado y la democracia han surgido recientemente, sugiriendo que en países con sistemas políticos más estables la articulación entre legalidad e ilegalidad no tiene lugar. Segundo, que el campo se ha desarrollado mediante estudios de caso, pero se ha prestado menos atención a las recurrencias y construcción de tipologías basadas en prototipos a partir de ellos. Tercero, que aunque la relación entre legalidad e ilegalidad ocurre tanto en países desarrollados como emergentes, esa articulación puede presentar diferencias entre ambos contextos. Si bien el artículo no propone una explicación definitiva, aporta una hipótesis sobre cómo podrían conceptualizarse.

\section{PALABRAS CLAVE:}

Estado, legalidad, ilegalidad, orden social

This article reflects on the relationship between legality and illegality in the conformation of the social order from three problematic knots. First, the fact that most of the studies focus on regions where the centralized state and democracy have recently emerged, suggesting that in countries with more stable political systems the articulation between legality and illegality does not take place. Second, the field has been developed through case studies, however, the recurrences and construction of typologies based on prototypes of them has not been explored. Third, although the relationship between legality and illegality exists in both developed and emerging countries, this articulation may present differences between both contexts. Even though the article does not propose a definitive explanation, it does provide a hypothesis on how they could be conceptualized.

\section{KEYWORDS:}

State, Legality, Illegality, Social Order 



\section{Introducción}

Este artículo tiene por finalidad aportar a la conceptualización sobre la manera como se constituye el orden social en situaciones donde lo legal y lo ilegal aparecen articulados. Examinaremos esa relación a través del vínculo entre las fuerzas de seguridad, actores del sistema político y miembros de la sociedad civil regularmente involucrados en actividades ilegales. El artículo se centra en el análisis de casos paradójicos, donde los agentes del Estado no siempre encarnan la norma sancionada por las organizaciones gubernamentales. En cambio, se vinculan con actores que transgreden sistemáticamente esas normas, generando órdenes sociales en los que se relativiza la frontera entre las instituciones del Estado y las organizaciones delictivas. El análisis de estas relaciones de colusión o connivencia estará fundado en estudios de caso. Si bien se consideran estudios realizados en América Latina, el foco no estará centrado exclusivamente allí; además, se incluirán países de otras regiones en desarrollo o con democracias emergentes como Europa del Este, y regiones desarrolladas, particularmente Norteamérica.

Mediante la inclusión de casos surgidos en distintos contextos, el artículo procura dos objetivos. Por un lado, mostrar que la comparación entre ellos permitiría discernir elementos recurrentes y divergentes presentes en estas formas de connivencia. Por otro lado, al elegir casos en países en desarrollo y desarrollados se intenta relativizar la forma en que tradicionalmente se han planteado las diferencias entre democracias emergentes, donde habitualmente se considera que existen Estados fallidos y órdenes sociales inestables, y países donde existirían Estados efectivos, democracias estables o consolidadas, y órdenes sociales estables (estas categorías se explicarán posteriormente). Lo que intentamos mostrar es que estas formas de colusión no son propias de un solo tipo de país o conjunto de ellos (desarrollados o en desarrollo), sino que ocurren, aunque tal vez de distinta manera, en varios contextos.

Es importante aclarar que, dado que la comparación se centra en un número limitado de casos, el objetivo que perseguimos no es presentar una tipología exhaustiva o una tesis concluyente. Por el contrario, intentamos sugerir hipótesis sobre algunas de las principales similitudes y diferencias que presentan estas formas de connivencia y cómo estas podrían derivar en ciertas formas de clasificación con potencialidad heurística. Así, si bien la casuística que presentamos no compone una muestra representativa por región o por tipo de casos, sí revela ciertas formas de recurrencia y variación que adquieren las distintas modalidades de colusión entre las fuerzas de seguridad, los agentes del sistema político y los miembros de la sociedad civil involucrados en actividades ilegales. Además, al incluir distintas regiones, se indica que estas formas de connivencia pueden configurarse en una variedad de contextos 
económicos y políticos y, aunque pueden presentar matices, no son exclusivas de algunos de ellos.

La próxima sección presenta una discusión conceptual sobre los vínculos entre legalidad e ilegalidad que pretende explicitar la perspectiva desde la cual se examinarán los casos en las distintas regiones. La segunda sección expone la casuística que ilustra la manera en que se produce este tipo de relación en distintos países. Posteriormente, se elabora una hipótesis sobre qué es lo que diferencia a esta forma de articulación en el orden social de países en desarrollo con Estados fallidos y órdenes inestables, respecto de las que tienen lugar en países desarrollados con Estados efectivos y un orden social más estable. En las conclusiones se discuten los aportes que permite esta perspectiva comparativa respecto a la conceptualización actual sobre la relación entre legalidad e ilegalidad en distintos contextos.

\section{La constitución del orden social: entre lo legal y lo ilegal}

Las consideraciones tradicionales sobre el vínculo entre legalidad e ilegalidad en la conformación del orden social han postulado a esas dos dimensiones como mutuamente excluyentes. Las concepciones clásicas, desde las teorías contractualistas, pasando por el funcionalismo y la tradición weberiana, han planteado al orden social como constituido por un conjunto de normas e instituciones asociadas que regulan los vínculos o formas de relación de los miembros de la sociedad. En esta perspectiva, la norma, cuando es legítima (colectivamente aceptada) es constitutiva del orden, mientras que la ilegalidad es lo que amenaza o acecha a ese orden. Más aún, en los planteamientos clásicos, quienes trasgreden la ley son aquellos que buscan obtener ventajas sobre el conjunto eludiendo o vulnerando las restricciones que rigen al resto de la sociedad. Así, la transgresión a la ley aparece como una amenaza al orden social, ya que socaba las bases que lo originan.

Esta teoría del orden implica una teoría del Estado, o al menos de una parte del mismo. Si la ley encarna el orden y el orden es el fundamento del vínculo social, el Estado aparece como la estructura institucional que encarna esa ley y opera como garante de ese orden. De forma tal que, en esta perspectiva, el Estado interviene como agente o actor portador de la ley para que la transgresión, cuando ocurre, sea reprimida y señalada como ilegítima.

Esta noción del orden y la ley tiene antecedentes en la forma como los padres del contractualismo, Hobbes o Rousseau, concebían al contrato social. Si bien ellos disentían respecto a cuál era la naturaleza humana (si el individualismo competitivo o la empatía y la cooperación), ambos coincidían en que la sociedad se constituía 
a partir de la aceptación de reglas que establecían formas admisibles de relación entre sus miembros. Esta era la concepción del orden social que sostenía Hobbes cuando afirmaba que el contrato social supone una mutua transferencia del derecho natural, según la cual alguien sacrifica su derecho a robar la comida de otro, porque ese otro sacrifica el derecho a robar la comida del primero (Skinner, 1997:66). Y esa misma noción estaba presente en Rousseau cuando indicaba que el 'contrato social se constituye cuando prima entre los hombres una equidad tal que todos se obligan a respetar los mismos principios y, por lo tanto, deben disfrutar de los mismos derechos' (Dent, 2008: 47).

Esta concepción del orden como un sistema de normas legítimo que regula los vínculos sociales incidió también en la concepción funcionalista de Comte en adelante. Aunque no es posible reconstruir exhaustivamente la secuencia aquí, la influyente metáfora de Durkheim (1985) sobre la conciencia colectiva como "cemento de la sociedad" replica e, incluso, profundiza esa concepción original. La noción de conciencia colectiva no solo plantea a la norma como fundamento del orden, sino que también supone la internalización de valores y categorías cognitivas compartidas (formas de ordenar la percepción del tiempo y el espacio, e identificar diversos grupos y estamentos sociales) como fundamento del mismo. En esta perspectiva, la subjetividad colectiva no es concebida como un mero regulador de los vínculos sociales, sino que es la condición misma para que el orden social exista. La ausencia de esos fundamentos, la anomia, conduce a vínculos conflictivos que, lejos de pensarse como inherentes a todo grupo social, se representan como una patología que amenaza su misma existencia. Así, la perspectiva funcionalista profundiza la mirada dicotómica adelantada por el contractualismo, ya que, a la vez que desarrolló una concepción que extiende los alcances del sustrato intersubjetivo en que se asienta el orden, lo explica como condición sine qua non para que este exista.

La visión weberiana comulga con esta tradición clásica, aunque desde una óptica ligeramente diferente. En Weber, la noción de orden subyace a su concepción del poder y la dominación (Bendix, 1979: 66). En esta perspectiva, el orden surge del reconocimiento de un conjunto de reglas que permiten, a la vez, que los individuos establezcan relaciones mutuamente referidas entre sí y reconozcan a una autoridad con capacidad de decisión y mando sobre el resto. Así, se constituye una identificación entre orden y régimen político. Esta implica que un régimen político se funda en instituciones de gobierno (el Estado) que tienen la capacidad de definir y administrar las normas que regulan los vínculos o relaciones sociales. De esta forma, la visión weberiana cristalizó la noción de que el orden social consiste en un conjunto de normas que regulan los vínculos entre los miembros de la sociedad, y que el Estado es quien encarna y administra ese orden normativo. Es así como 
este adquiere o posee el "monopolio del uso legítimo de la fuerza" en tanto ejerce ese rol de garante del orden (Weber 1998: 83). En definitiva, en esta perspectiva se plasma la premisa a partir de la cual se concibe al orden social como un conjunto de normas legítimas encarnadas por el Estado, la cual se contrapone a la transgresión normativa como amenaza a ese orden.

Algunos de quienes observaron desde esta óptica los procesos de conformación del Estado en distintas circunstancias y regiones plantearon una dicotomía entre Estados fallidos o frágiles y Estados efectivos o consolidados (Gros, 1996; Olivier, 2013). Los primeros pueden definirse como aquellos que no tienen la fortaleza o recursos suficientes para encarnar o preservar la ley; como contraposición, los segundos son aquellos que logran concretar ese papel como encarnación de la misma. En sociedades con Estados fallidos, la constitución del orden social sería más precaria o inestable, ya que estos no podrían, ni simbólica ni prácticamente, defender los fundamentos del orden; es decir, el conjunto de reglas, principios y categorías que regulan los vínculos sociales adolecerían de un respaldo institucional limitado $\mathrm{y}$, por ende, su vigencia efectiva como reguladores de los vínculos sería menor. Así, la estabilidad institucional sería precaria, y el conjunto de normas y principios que regulan los vínculos sociales serían más lábiles y fluctuantes. Donde existen Estados efectivos, el respaldo institucional sería mayor y, con ello, la vigencia de las normas, valores y categorías sociales también sería más duradera y efectiva dando lugar a órdenes más estables. Normalmente, se ha presentado a los Estados fallidos como característicos de países en desarrollo (de industrialización tardía e incompleta), así como con regímenes republicanos recientes y con relativa legitimidad social,mientras los Estados efectivos serían más propios de países desarrollados y con instituciones republicanas más estables y de mayor legitimidad social.

Ahora bien, las denominaciones de frágiles o fallidos para algunos Estados han sido fuertemente cuestionadas, en parte porque estas categorías han resultado difíciles de operacionalizar (Ferreira, 2016), pero, además, porque la connotación que poseen estos términos ha influido negativamente en la percepción respecto a algunos países o regiones, y legitimado políticas que reproducen su lugar subordinado en el contexto internacional (Grimm; Lemay-Hébert; Nay, 2014; Nay, 2013). Finalmente, y más importante para nosotros, la idea de una frontera que divide taxativamente la legalidad y la ilegalidad no es sostenible. Al menos desde las contribuciones de Barrington Moore (1989) y Charles Tilly (2006), se ha hecho obvio que el proceso mismo de constitución del Estado moderno que supuestamente encarna el sistema legal actual implicó la sinergia entre actores legales e ilegales. También es claro que hay una compleja articulación entre legalidad y legitimidad, por lo que el principio de que todo sistema legal expresa necesariamente un orden legítimo es, al menos, una 
simplificación. Es una obviedad señalar que los grados de legitimidad normativa varían según el tipo de norma del que se trate, y según el grupo social en que rige la norma.

Por eso, el Estado no encarna, sin más, un orden legal y legítimo, sino una pretensión de orden que posee grados diversos de legitimidad en el conjunto social. De esta manera, existen transgresiones a la norma oficial encarnada en el Estado (ilegalidades) que expresan un orden normativo alternativo con su propia legitimidad y posibilidades de constitución del orden, pero que difiere de la norma oficial. Más aún, por momentos, el propio Estado (o algunos de sus agentes) tensionan el mismo orden normativo que pretendidamente encarnan, revelando la ambigüedad que caracteriza, finalmente, a todo orden social.

En Tilly (2006: 2), esto puede notarse cuando señala que la constitución del Estado nación, si bien ocurrió a través de diversas vías, siempre tuvo como uno de sus componentes fundamentales la violencia organizada como forma de extracción de los recursos necesarios para extender su poder o dominación social y territorial, ya fuera a través de la guerra, la venta de protección o la connivencia con la delincuencia. De manera algo más tácita, pero de todas maneras coincidente, Barrington Moore (1989) señala que la inclusión de la clase subalterna al "contrato social implícito" en el que se funda el régimen de dominación moderno incluye la coacción, la fuerza, el miedo o el fraude. Si bien no son los fundamentos de una dominación estable, estos pueden formar parte del proceso de su constitución (Moore, 1989: 23). En suma, aunque no podemos profundizar en los matices que diferencian los trabajos de Tilly y Moore en este punto, es claro que, de distintas maneras, ambos sugieren que el orden social no se constituye a partir de la exclusión recíproca entre lo legal y lo ilegal; en cambio, resulta de complejas y cambiantes articulaciones entre ambos.

Ahora bien, en la medida en que esta segunda alternativa presenta una concepción más realista de cómo se configura el orden social, deja planteada una nueva interrogante. Mientras habría que descartar los contrastes simplistas entre órdenes donde lo legal y lo ilegal se articulan, y órdenes en que no lo hacen: ¿no habría que preguntarse por las diversas formas en que se produce esa asociación? O, llevada la pregunta a un plano más operativo: ¿no sería posible diferenciar diversos tipos de órdenes según la variedad de maneras en que se producen las relaciones entre legalidad e ilegalidad?

En este sentido, la forma como se ha llevado adelante la investigación en este campo presenta una doble complejidad. Por un lado, el análisis de las relaciones entre legalidad e ilegalidad se ha realizado, mayormente, mediante estudios de caso. Estos estudios han efectivamente extendido la demostración de que el orden social se configura muchas veces en la articulación entre lo legal y lo ilegal. Sin embargo, la falta de perspectivas comparativas en la presentación de la casuística sugiere que 
cada caso es único, y no ha habilitado a una caracterización más general de esas formas de articulación a partir de sus posibles similitudes y diferencias.

Por otro lado, los estudios de caso que muestran articulaciones entre lo legal y lo ilegal se concentran casi exclusivamente en países en desarrollo con democracias emergentes. Por eso sugieren, aunque tácitamente, que este tipo de articulación solo ocurre en estos contextos, y estaría casi ausente en regiones donde el proceso de industrialización ha sido más temprano y completo, y donde el sistema republicano goza de una existencia más extendida y mayor legitimidad social. No obstante, es posible encontrar situaciones en países desarrollados y con democracias consolidadas que indican la existencia de este tipo de articulaciones también en esos contextos.

En las próximas páginas presentaremos una serie de estudios de caso que ilustran diversas formas de constitución de órdenes sociales en los que se articulan lo legal y lo ilegal o, más concretamente, agentes estatales, como la policía y actores del sistema político, con sectores de la sociedad civil recurrentemente involucrados en actividades ilegales. Como adelantamos, no nos proponemos, en un artículo breve, presentar una casuística exhaustiva de los diversos tipos de órdenes, ni demostrar empíricamente una tesis en particular. Más modestamente, a partir de la comparación entre casos, pretendemos mostrar el valor heurístico de identificar algunos factores o condiciones, algunas recurrentes y otras variables, que permitan discriminar entre distintas formas de articulación entre legalidad e ilegalidad.

Los casos presentados incluyen a países en desarrollo y con democracias emergentes, y otros desarrollados y con democracias estables. Si bien, como señalamos, el propósito es sugerir que la articulación entre la legalidad y la ilegalidad ocurre en ambos tipos de países, no se trata de indicar que esta ocurre exactamente de la misma forma en ambos casos. La intención es identificar condiciones que permitan establecer diferencias entre ellos, más allá de esa continuidad. En un conocido artículo, Guillermo O’Donnell (2002) ya plantea que, a diferencia de lo que sucede en regímenes republicanos consolidados, en las nóveles democracias de Europa del Este y Latinoamérica la mayor desigualdad social y debilidad institucional limita la capacidad de los sectores más postergados de acceder a las instituciones jurídicas que garantizan sus derechos. En el mismo sentido concurren los aportes de Helmke y Levitsky (2006), al indicar que las instituciones republicanas en Latinoamérica no alcanzan un funcionamiento pleno, y compiten con otras (informales) que limitan la vigencia de los derechos cívicos; algo que, en el mismo libro, confirma Brinks (2006), al analizar la impunidad policial en Argentina y Brasil.

Sin embargo, en este caso pretendemos proponer una tesis distinta, aunque no contradictoria, a las anteriores. Para ello, retomaremos la perspectiva que tempranamente introdujo Bronislaw Malinowski (1969), mostrando la forma en que, efectiva 
y concretamente, las normas regulan las relaciones sociales en la vida cotidiana. De manera interesante, los relatos etnográficos que presenta muestran cómo se articula la legalidad con la tolerancia a la ilegalidad en la convivencia diaria. Sin embargo, también pone en evidencia los límites de esa tolerancia y la manera como estos intervienen en la constitución del orden social. Como veremos, con base en esta observación resulta posible proponer hipótesis sobre la forma en que se diferencia el orden social en países más y menos desarrollados, pero sin asumir que la articulación entre lo legal y lo ilegal ocurre solo en estos últimos.

\section{Estudios de caso}

Los estudios de caso que presentamos fueron tomados de contextos diversos: Europa del Este, América Latina y Norteamérica. Ya señalamos que esta selección no pretende agotar la casuística de vinculaciones entre lo legal y lo ilegal en cada región, ni supone casos representativos de cada una de ellas, sino que, simplemente, indican posibles formas de relación en distintos contextos. En este sentido, no deben tomarse como tipos ideales weberianos, ya que no representan modelos teóricos que sintetizan, a partir de abstracciones, procesos del mismo tipo. Los casos que presentamos tienen, mejor, el carácter de prototipos, en el sentido que los plantea la antropología cognitiva (D’Andrade, 1995). Es decir, referencias empíricas a partir de las cuales es posible clasificar variantes en función de los grados de similitud o diferenciación que presenten otros casos respecto a ellos. Aquí solo intentaremos una primera aproximación a este tipo de ejercicio comparativo con el objetivo de mostrar su valor heurístico, pero no pretendemos elaborar un sistema completo de clasificaciones con base en él. Esto supondría una comparación mucho más extensa y exhaustiva a la que es posible en este trabajo.

\section{Rusia}

La desintegración de la Unión Soviética, en 1991, ha sido señalada como un hito a partir del cual proliferó el crimen organizado, no solo en Rusia, sino en el conjunto de países que componían el bloque comunista hasta entonces (Albini et al., 1995; Kukhianidze, 2009; Kupatadze, 2012). La bibliografía revela que durante el régimen comunista existía un Estado fuertemente centralizado con amplia capacidad de regulación del orden social; régimen que no permitía la articulación de poderes paralelos externos a un Estado con capacidad de administrar recursos importantes o territorios más allá de él. Solo existían pequeños grupos juveniles con alguna 
capacidad de control sobre la calle, sobre todo en lapsos y espacios marginales (la noche, las periferias urbanas, etc.) y formas de criminalidad funcionales al poder de Estado. Por ejemplo, un sistema de corrupción y constitución del mercado negro de funcionarios que promovían y comercializaban los productos generados por la industria pública más allá del control oficial de esa producción. Es decir, se alimentaba un mercado negro con una producción que estaba por fuera de la oficialmente planificada por el Estado.

Con la caída del Estado soviético, ese régimen de regulación centralizada decayó, lo que dio lugar a una reconstitución del orden con una nueva lógica. Según las caracterizaciones sobre el proceso posterior a la descomposición del régimen comunista, lo que siguió fue una penetración o captura del Estado por parte del crimen organizado (Shelley, 1994; Wedel, 2003). Este fue apropiándose de los negocios que surgían con el incipiente capitalismo, en parte explotando actividades ilegales, como el tráfico de drogas, la prostitución, la comercialización de autopartes robadas, etc., pero también extorsionando a actores de la economía legal o formal, y apoderándose, por el uso de la fuerza, de los recursos que iban quedando vacantes a partir de la retirada del Estado. Así, algunas de las antiguas e incipientes bandas juveniles que se fortalecieron utilizando la fuerza indiscriminada como recurso, y en algunos casos aliándose con los antiguos actores del Estado para formar organizaciones de mayor envergadura, fueron tomando control de los nuevos negocios posibilitados por los cambios en la organización política y económica.

Existen diversos estudios que ilustran estas dinámicas en los antiguos Estados de la Unión Soviética (Galeotti, 2002; Shelley; Scott; Latta, 2017). Aunque ciertamente no es un caso único, la compleja evolución del vínculo entre el crimen organizado y los agentes del Estado en la provincia rusa de Tartaristán es particularmente ilustrativa de estas dinámicas (Stephenson, 2017). En ese contexto, surgieron bandas juveniles que inicialmente no tenían pertenencia a estructuras mayores, sino que se trataba de grupos que lograron control territorial y establecieron un sistema de venta de protección a los nuevos comercios emergentes, como mercados callejeros, kioscos, cafés, etc. A su vez, las bandas juveniles se articularon progresivamente en grupos del crimen organizado, cuyos jefes controlaban negocios de mediana y gran envergadura, como bancos, industria química, entre otros.

En la situación de debilidad del Estado para imponer la ley y el colapso de su capacidad de garantizar bases mínimas de bienestar, algunas de estas organizaciones mafiosas se transformaron en proto-Estados. Así, constituyeron una suerte de gobierno privado y alternativo, en el que se articulaban la venta de protección y la extorsión a comercios locales y la provisión de grados limitados de bienestar a la población. Por ejemplo, estos grupos 
daban a los residentes dinero y vegetales gratuitos. La Zhilka (bandas juveniles) protegía a los residentes de los crímenes comunes no cometidos por la banda, e instalaba aberturas de seguridad en la entrada de los edificios o departamentos. Su poder en sus áreas de influencia era casi absoluto. Los miembros más jóvenes establecían cordones y erigían barricadas de concreto sobre las calles que conducían a su territorio, controlando los vehículos entrantes ${ }^{1}$. (Stephenson, 2017: 135)

Esto permitió a los grupos construir espacios desregulados, donde las instituciones oficiales, como la policía, tenían un poder extremadamente limitado, incluso al punto de que la acción policial solo podía ocurrir con el consentimiento de estos grupos, que tenían la capacidad de eliminar o, más habitualmente, corromper el control de los policías que pretendían combatirlos.

La Zhilka estableció un sistema de estrecha vigilancia sobre su territorio que no permitía a la policía llevar adelante operaciones secretas en el área (Safarov, 2012, pp. 79-80; Beliaev and Sheptitskii, 2012, pp. 225-226). En todo Kazan los grupos criminales eran dominantes, intimidando o incluso matando a los oficiales de policía que trataban de combatirlos, o sobornando a aquellos que no los combatían. Enclaves criminales del mismo tipo, pero organizados por otro grupo llamado Vory, aparecieron en otras zonas de Rusia, por ejemplo, en el lejano este ${ }^{2}$. (Holzlehner, 2014: 117)

Sin embargo, este régimen emergente en la década de 1990 fue declinando a medida que el Estado centralizado fue recuperando su capacidad de control en los primeros años del siglo XXI. Ese proceso de recuperación no produjo la desarticulación absoluta de estos grupos, sino su rearticulación hacia un nuevo tipo de vínculo entre legalidad e ilegalidad. Los jefes de los anteriores grupos que habían logrado controlar grandes compañías abandonaron el uso de la fuerza como elemento de extorsión y comenzaron a utilizar la colusión con actores del gobierno. Más que el pago directo de sobornos, el mecanismo elegido fue el patrocinio o donación a instituciones oficiales. Así, muchos jefes de antiguos grupos mafiosos hacían donaciones o patrocinaban actividades de los departamentos de policía, los grupos de combate al crimen organizado, la procuraduría pública, etc.

La corrupción, el intercambio de dinero por recursos administrativos, ahora tomó la forma más institucionalizada del "patrocinio". Avtoritety [grupos del crimen organizado] usaban las compañías que poseían o controlaban legalmente para transferir fondos a los

1. Traducción propia.

2. Traducción propia. 
departamentos de policía, la procuraduría pública y los grupos de combate del crimen organizado para la compra de equipamiento de oficina, la renovación de edificios o nuevos medios de transporte. Como retribución, la policía otorgaba protección a las bandas de crimen organizado. Por ejemplo, tal como lo expresó un entrevistado: "en ciertos casos Avtoritety ayudan a la policía con sus obshchaki [fondos propios], porque de esta manera evitaban un control estricto de las calles.” Esta cooperación genera beneficios mutuos3. (Stephenson, 2017: 141)

Notablemente, este tipo de articulación no implicó la creciente incapacidad de las agencias de seguridad de controlar el crimen, sino un paradójico incremento. Si bien la corrupción personal no desapareció, los agentes que no eran corruptos a nivel personal podían utilizar las redes en las que se articulaba la corrupción institucional para perseguir delitos que no afectaran directamente a sus socios y, a su vez, estos se cuidaban de desarrollar actividades que pudieran afectar de manera directa el prestigio de las fuerzas de seguridad.

Este tipo de asociación implicó también el desarrollo de vínculos personales que, incluso, instituyeron códigos morales que afectaban la modalidad de los pagos de sobornos a nivel personal. La transacción en dinero en efectivo comenzó a ser mal vista y, en cambio, otras prácticas de sociabilidad fueron sustituyendo ese mecanismo inicial.

A medida que se estrechaban los lazos personales entre los oficiales de policía y los criminales, ambas partes sintieron que el intercambio en dinero efectivo era inapropiado. En lugar de dinero efectivo, los líderes de la gruppirovki [mafia] comenzaron a retribuir a los oficiales de policía con favores personales, incluyendo la posibilidad de comprar bienes con enormes descuentos en los negocios de los gruppirovki, estacionamiento gratuito y la renovación de las viviendas, vacaciones pagadas y otras ventajas ${ }^{4}$. (Salagaev; Shashkin; Konnov, 2006:10)

Es claro, entonces, que la evolución de un sistema a otro implicó una transformación de los vínculos entre lo legal y lo ilegal. No es que esa relación haya desaparecido, sino que se redefinió, en este caso, de acuerdo con el poder relativo de cada una de las partes.

Ahora bien, el punto que queremos resaltar aquí no parte tanto de profundizar en el caso ruso, sino de observar que esta mutación muestra dos tipos de articulación

3. Traducción propia.

4. Traducción propia. 
entre lo legal y lo ilegal que son recurrentes. En uno de esos tipos, se constituye una articulación en la que lo ilegal subordina y condiciona a la legalidad, y otra, tal vez menos obvia y por eso más interesante, la ilegalidad, en algunos sentidos, alimenta y permite la existencia de la legalidad. Es decir que, en un caso que podríamos llamar colusión, la articulación entre los actores, si bien opera como sustituto de unas instituciones oficiales debilitadas, se desarrolla por la subordinación de una legalidad débil frente a una ilegalidad fuerte, que impone sus intereses en su campo de acción en desmedro de otros.

En el otro caso, el vínculo entre la legalidad y la ilegalidad tiene más el formato de la sinergia; es decir, el vínculo no se funda en una legalidad débil y una ilegalidad fuerte, sino en una relación en la que la legalidad se potencia en su vínculo con lo ilegal. En estos casos, no parece existir un actor con capacidad de imponer unilateralmente intereses, sino, más bien, configuraciones de vínculos sociales en los que estos se dirimen coyunturalmente. A estos dos casos podría agregarse un tercero que el ejemplo ruso no ilustra, pero que se manifiesta en algunos de los estudios sobre países latinoamericanos.

\section{Argentina y Brasil}

Por ejemplo, varios estudios de caso en Brasil y Argentina muestran la articulación entre la legalidad y la ilegalidad mediante lo que podríamos llamar la administración discrecional de la norma. A diferencia de lo que ocurre en los casos rusos, en estos, los agentes del Estado no mantienen una connivencia estable con las organizaciones delictivas, sino que por momentos participan de la actividad ilegal y, en otras circunstancias, la reprimen de acuerdo con las conveniencias. Dicho de otra forma, los agentes del Estado intervienen contingentemente permitiendo, reprimiendo y entrando en complicidad con actores de la sociedad civil involucrados en actividades ilegales según la ecuación coyuntural de costos y beneficios para las partes involucradas.

Para ser claros, esta no es la única forma en que las fuerzas de seguridad, agentes del sistema político y miembros de organizaciones criminales se vinculan entre sí en América Latina, en general, o en Brasil o Argentina, en particular. Como ha sido reportado numerosas veces, además de estas formas de organización lábiles o cambiantes, existen también organizaciones estables que están en colusión con agentes del Estado como los cárteles mexicanos, las maras centroamericanas o los comandos en Brasil (Desmond-Arias; Barnes, 2016; Gledhill, 2018; Pansters, 2018; Savenije, 2014). Por eso-y como ya aclaramos-, los casos que presentamos no deben ser considerados como representativos de la región, sino como un tipo de articulación que ilustra una de las formas que pueden adquirir estos arreglos y que no ha sido tan 
frecuentemente considerada, sugiriendo una variante que podría ser sumada a una categorización de las diversas modalidades que pueden asumir los vínculos entre los agentes del Estado y las organizaciones delictivas.

En el caso de Argentina, esta forma de connivencia lábil entre los agentes del Estado (fuerzas de seguridad y el sistema político) y las organizaciones delictivas se manifiesta, entre otras cosas, en las ferias clandestinas de ropa (Dewey, 2015)5. Estas ferias ocupan extensos predios en zonas conocidas del sur de la ciudad de Buenos Aires y operan fuera del marco legal. No cumplen con la ley tributaria ni con la ley de marcas, y comercializan prendas confeccionadas en talleres que son también clandestinos (no cumplen las leyes laborales o sanitarias, etc.). A su vez, la distribución y el cobro del canon de los locales en las ferias está en manos de bandas (normalmente barras bravas de equipos de fútbol) que operan con base en la amenaza y la violencia, y desarrollan sus propios comercios paralelos -esencialmente el de drogas y la venta de protección-.

$\mathrm{Al}$ estar ubicadas en zonas conocidas de la ciudad capital, estas ferias tienen visibilidad nacional y su carácter clandestino es de público conocimiento. Así, no existe forma de que estas operen fuera de la visión o el alcance de las agencias estatales. Lo que permite su existencia es una complicidad con el sistema político y las fuerzas de seguridad que se financian, en parte, con una suerte de tributación informal que recogen de quienes administran la feria, los cuales aportan a las campañas políticas y, también, realizan contribuciones a la policía, que muchas veces sostiene su propio funcionamiento a través de ellas (entre otras cosas, financian el combustible para los patrulleros).

Sin embargo, han existido episodios que llevaron al cierre temporario de varias de estas ferias. Estallidos de violencia entre quienes administran diversas actividades que tienen lugar en la feria llevaron a sectores del sistema político y de las fuerzas de seguridad a intervenir y clausurar esta actividad. Incluso, en 2017, encarcelaron al dueño de la más grande feria en el sur de la ciudad de Buenos Aires, aunque fue excarcelado en 2019. De hecho, estas medidas han sido siempre temporarias. A medida que las repercusiones de los conflictos amenguan, actores de la justicia en connivencia con el sistema político encuentran la manera de justificar la anulación de causas judiciales y la reapertura de las actividades de las ferias. Así, se produce una administración de la norma según la conveniencia circunstancial de los actores involucrados. No se trata de lazos estables o permanentes, sino de alianzas circunstanciales que fluctúan según las circunstancias políticas y económicas.

5. Otro caso similar se produce en la comercialización de autopartes robadas donde también se observan arreglos lábiles entre las fuerzas de seguridad, agentes del sistema político y organizaciones delictivas (Dewey, 2012; Míguez, 2014). 
En el caso de Brasil, esta forma de connivencia puede reconocerse, entre otras cosas, en el sistema de apuestas clandestinas, conocidas como el juego del bicho (Misse, 2014). Este sistema ha perdurado durante varias décadas y se ha extendido desde Río de Janeiro a otras ciudades importantes del país, como San Pablo, Minas Geráis o Espíritu Santo. El sistema de apuestas tiene una organización territorial: quienes levantan las apuestas se ubican en puntos conocidos de la ciudad, y utilizan un talonario donde registran la apuesta hecha por cada participante, dándole una constancia de la misma. Cada ciudad está dividida en zonas propias de cada recaudador y, a veces, existen disputas entre ellos por el monopolio de estas áreas.

Los capitalistas que respaldan las apuestas en cada área (bicheiros) son conocidos y mantienen intercambios con políticos locales, autoridades provinciales y policías locales. Además, establecen un vínculo clientelar con los vecinos, realizando aportes a organizaciones barriales, como los clubes vecinales o las escuelas de samba. Sin embargo, estos arreglos no son siempre estables. Como lo muestra el propio estudio de Misse (2014: 70), puede ocurrir que intereses de políticos en competencia desestabilicen estas alianzas, lo que puede resultar en la disolución de los acuerdos, al menos temporalmente. En este sentido, Misse (2018) ha llamado la atención sobre el hecho de que más que sistemas estables de acuerdos, estos funcionan como sistemas de transacción inestables regulados por el cálculo político, la circunstancial correlación de fuerzas entre las partes o la relevancia de los intereses económicos en juego.

Ahora bien, aunque los acuerdos pueden ser lábiles, Sobering y Auyero (2019) han llamado la atención sobre el impacto más prolongado que pueden tener en la percepción de la ley o de las fuerzas de seguridad. Aunque la connivencia entre las organizaciones criminales y los agentes estatales puede sufrir fluctuaciones, de todas maneras, generan cierto cinismo sobre estas instituciones. Por ello, los ciudadanos comunes (sobre todo de barrios pobres) son renuentes a invocarlas cuando se ven afectados por organizaciones delictivas o sus miembros y, paradójicamente, en ciertas circunstancias, estos últimos tienen más posibilidades de lograr su cooperación o anuencia. De esta manera, se constituye un orden en donde los agentes del Estado (o algunos de ellos) alternan su rol entre actuar como encarnación de la norma oficial o como agentes de normas clandestinas, pero que de todas maneras hacen efectivas.

\section{Estados Unidos}

Un último caso se refiere a la forma en que se articulan los agentes del Estado y de la sociedad civil involucrados en la actividad legal en Estados Unidos. Notablemente, las formas de colusión entre el sistema político, las fuerzas de seguridad y las organizaciones criminales en países desarrollados y democracias estables como la 
norteamericana no han formado parte de las referencias con base en las cuales se construyeron conceptos como estados fallidos o débiles. Como señalamos, se elaboraron casi exclusivamente en relación con los países en desarrollo con democracias emergentes. No se tomaron en cuenta los matices que surgirían de considerar este tipo de vínculos en los países con Estados supuestamente efectivos o fuertes.

Sin embargo, al menos en los Estados Unidos estos vínculos han sido una temática recurrente en algunos de los estudios más reconocidos en el área, al menos desde la década de 1940 o 1950. Por ejemplo, Whyte (1943) revela cómo grupos de jóvenes ayudaban a los dirigentes políticos vecinales a organizar fraudes durante las elecciones, al punto que el propio Whyte quedó involucrado en uno de ellos. Por su parte, Cloward y Ohlin (1963) muestran cómo muchos políticos locales surgían de la actividad ilegal, como las apuestas clandestinas, actividad que abandonaban una vez habían acumulado suficiente poder y recursos como para pasar a actividades legales igualmente rentables.

Ahora bien, aunque algunas etnografías relativamente recientes han tendido a ignorar este tipo de vinculación (Bourgois, 2011; Vigil, 2003), no parece haber desaparecido. De hecho, en un estudio detallado, Sanchez Jankowski (1991: 219) muestra que existen articulaciones entre los políticos locales, las fuerzas de seguridad y las organizaciones criminales en las ciudades de Nueva York, Boston y Los Ángeles, aunque varían según la cultura cívica vigente en cada una de ellas. Por ejemplo, con base en los testimonios de algunos líderes de las bandas callejeras de los barrios marginales y de los propios dirigentes políticos de estas ciudades, el autor da cuenta de un complejo sistema de intercambios. A falta de estructuras partidarias al interior de los distritos más pobres, los dirigentes políticos utilizan a las bandas como recurso en las campañas electorales de distintas maneras: 1) distribuyen propaganda impresa en el barrio; 2) colocan carteles de propaganda en lugares públicos; 3) llevan a las personas a votar en el día de las elecciones; 4 ) a veces presionan a los vecinos para que voten a un determinado candidato; 5) algunas bandas económicamente poderosas aportan fondos para financiar campañas políticas; 6) a veces las bandas recaudan fondos de campaña mediante la coerción, de manera compulsiva, entre los vecinos; y 7) en algunas ocasiones, las bandas boicotean las campañas de políticos opositores.

Las retribuciones a estos favores no son inmediatas y tampoco específicas, aunque sí se hacen efectivas eventualmente. Estas pueden consistir en ayuda para conseguir puestos de trabajo, normalmente en la administración pública, aunque no exclusivamente en ella; en otros casos, el pago puede ser directamente en dinero o en la provisión de drogas, a veces para el propio consumo y otras para su comercialización. La retribución preferida de algunas bandas es la intervención de los políticos para moderar la interferencia de las fuerzas de seguridad, particularmente de la policía 
local, en sus actividades. Finalmente, puede existir la provisión de locales para desarrollar sus actividades, generalmente de tipo recreacional, aunque a veces eran utilizados para almacenar bienes robados (Sanchez-Jankowski, 1991: 222).

A diferencia de lo que muestran los casos de América Latina o Rusia, lo que destaca este estudio es el esfuerzo de todas las partes involucradas para mantener la discreción respecto de este tipo de intercambios. En general, la transacción entre los políticos y los líderes de las organizaciones criminales no se da de manera personal, sino que existen mediadores, frecuentemente dirigentes de organizaciones vecinales, que llevan adelante la transacción, justamente para evitar vínculos directos. De hecho, el carácter relativamente indefinido de los términos de intercambio forma parte de esta discreción, incluso, algunos de los testimonios recogidos por Sanchez Jankowski (1991:223) ponen en evidencia que los líderes de las bandas reconocen que las demandas directas o inmediatas probablemente serían rechazadas, justamente para disimular el carácter transaccional del vínculo.

Ahora bien, si este tipo de transacción se da en todas las ciudades, existen diferencias en cuanto a la aceptación que estas tienen en los distintos contextos, y los esfuerzos para ocultarlas que se hacen consecuentemente. En ciudades donde la actividad partidaria incluyó el manejo de sistemas clientelares extendidos, como Nueva York y Boston, hay una mayor naturalización de este tipo de transacción entre la política y las organizaciones criminales. En cambio, en Los Ángeles, donde las prácticas clientelares han sido menos preeminentes y la actividad política se valora como servicio público, estas formas de colusión entre la política y el delito reciben una mayor condena social. Si bien las transacciones de todas formas tienen lugar, existe mayor desconfianza entre las partes y una mayor preocupación por disimular estas relaciones.

En suma, pese a que conceptos como Estados fallidos o débiles han tratado a la colusión entre agentes estatales y organizaciones criminales como una particularidad de las democracias emergentes o los países en desarrollo, etnografías tradicionales y recientes indican que estos vínculos también pueden ocurrir (y de hecho han tenido lugar) en países industrializados y democracias consolidadas, como la estadounidense. Sin embargo, vale la pena detenernos en el notorio esfuerzo que hacen las partes involucradas por disimular esas vinculaciones, mostrando que el nivel de naturalización o tolerancia es comparativamente bajo. De hecho, el contraste entre Los Ángeles, de un lado, y Nueva York o Boston, de otro, indica que esta variación influye fuertemente en cómo se desarrollan y en el grado de visibilidad que pueden tener estos vínculos.

De esta forma, aunque podríamos concluir que la articulación entre lo legal y lo ilegal es parte de la constitución del orden social en casi todos lados, tampoco parece prudente saltarnos las diferencias. Si, como vimos, puede haber distintos 
tipos de articulación entre legalidad e ilegalidad, también los grados de legitimidad o tolerancia a esos vínculos pueden variar de una sociedad a otra. Y si, por un lado, una de las razones por la que, frecuentemente, esos vínculos no se consignan en los trabajos sobre los países desarrollados y democracias estables es el prejuicio de que estos solo son una rareza exótica de sociedades menos desarrolladas, otra razón posible es que en esas sociedades no son tan visibles y aceptados.

En este sentido, el caso norteamericano representa una variante donde, como en el comercio clandestino de prendas o de autopartes robadas, existen acuerdos fluctuantes entre los agentes del Estado y formas organizadas de actividad delictiva. Sin embargo, la diferencia en este caso parece ser la intensidad del vínculo y el grado de visibilidad que este adquiere. Si, en el primer caso, el tipo mismo de actividad la hace inocultable y requiere una fuerte articulación entre las partes; en el segundo, los términos de la transacción no requieren relaciones tan estrechas ni visibles. De hecho, las actividades involucradas no son en sí mismas públicas y hay un destacado esfuerzo, de todas las partes involucradas, por disimular los acuerdos.

\section{Discusión}

La casuística presentada sugiere dos de las cuestiones que planteamos inicialmente. En primer lugar, pone en evidencia que existe una variedad de formas como se articulan lo legal y lo ilegal que podría dar lugar a una clasificación de esa misma casuística. En segundo lugar, indica que estas formas de constitución del orden social no se producen solo en países en desarrollo o en democracias emergentes, sino que pueden tener lugar en países con industrialización avanzada e instituciones republicanas más estables.

En relación con la primera cuestión, si bien no pretendimos avanzar en una taxonomía exhaustiva, los casos presentados revelan diversos formatos de articulación entre agentes del Estado y miembros de la sociedad civil involucrados en organizaciones delictivas. Estas variaciones no solo tienen lugar de un país a otro, sino también muestran modulaciones en el tiempo dentro de una misma sociedad. Como señalamos, algunos casos ilustran situaciones donde aparece una articulación en la que lo ilegal subordina y condiciona a la legalidad: contextos donde organizaciones ilegales fuertes subordinan a instituciones legales débiles, constituyendo un orden donde las primeras imponen sus intereses en desmedro de otros.

Otros casos ilustran situaciones donde el vínculo entre la legalidad y la ilegalidad tiene más el formato de la sinergia, pues no existe una legalidad débil y una ilegalidad fuerte, sino una relación donde la legalidad se potencia en su vínculo 
con lo ilegal. Una tercera situación, ilustrada por los casos de Brasil y Argentina, revela articulaciones más lábiles, donde no hay formas estables de colusión entre las agencias del Estado y las organizaciones delictivas. En estos casos, la articulación entre legalidad e ilegalidad se produce mediante la administración discrecional de la norma. Las agencias del Estado imponen el marco legal o suspenden su imposición de acuerdo con sus posibilidades e intereses coyunturales. El caso norteamericano se ajusta en parte a este esquema, solo que con mayores niveles de discreción. En este caso, no solo las transacciones son ocasionales y lábiles, sino que, en comparación con los casos latinoamericanos, esa intermitencia y labilidad se relaciona con la importancia de que no se vuelvan excesivamente (o intolerablemente) evidentes para la opinión pública.

Es claro que esta tipología incipiente no agota las formas de recurrencia y variación que pueden asumir estos vínculos. Tampoco ha sido nuestra pretensión agotarla, ni el hecho de que hayamos escogido casos de distintas regiones supone que estos muestren contrastes sistemáticos entre ellas. Lo que sí indican estos ejemplos es que estas diversas formas de colusión pueden ocurrir en distintos contextos (no son patrimonio exclusivo de una determinada región o tipo de país) y, también, que existen ciertas regularidades que darían paso, en un ejercicio comparativo más extenso y exhaustivo, a la constitución de alguna forma de clasificación que permita una mayor comprensión de estas dinámicas.

En relación con la segunda cuestión, nuestro interés no consistió solo en mostrar que este tipo de arreglos ocurre en países desarrollados y en desarrollo, sino también en tratar de identificar alguna forma de dar cuenta de las distintas maneras en que ocurre en uno y otro contexto. Para eso, propusimos partir de un clásico estudio de Malinowski (1969) sobre las formas como ocurre la transgresión en las interacciones cotidianas, donde se buscaba relativizar, justamente, la influyente visión de Durkheim según la cual la violación a la norma siempre implicaba una amenaza a la cohesión grupal. A través de relatos sobre la vida cotidiana, Malinowski revelaba que, si bien las normas operan como referencias o pautas ideales de vinculación social, a su vez coexisten con transgresiones toleradas o consentidas que facilitan el equilibrio entre los distintos intereses que entran en juego en situaciones donde las normas deben ser aplicadas. La estabilidad del orden social no depende exclusivamente de que se respeten las normas, sino también de cierta tolerancia a la transgresión que impide que estas generen perjuicios excesivos para alguno de los actores sociales involucrados. Sin embargo, las historias de la vida cotidiana que presenta Malinowski revelan también los límites a esta tolerancia e ilustran el hecho de que, aunque cierto grado de flexibilidad es inherente a la vigencia de la norma, existen límites que impiden que esta se diluya por completo. 
Un episodio particularmente revelador refiere al tabú del incesto que regía a los vínculos entre primos paralelos (descendiente de hermanos del mismo género) en las islas Trobriand. Pese a que los romances entre ellos estaban prohibidos, la transgresión a esa norma era tan frecuente como tolerada. Sin embargo, Malinowski (1969) cuenta un incidente en el que un pretendiente despechado denunció públicamente una relación incestuosa entre primos, lo que resultó en el suicidio ritual del varón. La situación revela entonces los límites de la tolerancia a la transgresión: mientras pudiera pretenderse que esta era desconocida, podía ser tolerada, pero cuando se volvió flagrante y no podía ignorarse, la sanción fue aplicada con todo rigor.

El caso sugiere que la obviedad de la transgresión opera como límite a la tolerancia. Las razones detrás de este hecho no son plenamente develadas por Malinowski. Sin embargo, el caso sugiere que lo que permitía la tolerancia cuando la transgresión aún no se había denunciado públicamente era que la comunidad podía pretender que la ignoraba y que, por lo tanto, la norma continuaba vigente, pero al ponerse en evidencia su vulneración esta ficción ya no podía mantenerse. Es decir, frente a la imposibilidad de negar la transgresión, la falta de sanción implicaría la puesta en duda de la existencia misma de la norma. En este contexto, la única forma de mantener la creencia en la norma es que en los casos de flagrancia la sanción se aplique con todo rigor, aunque en la cotidianeidad la transgresión sea tolerada mientras pueda pretenderse que no está ocurriendo y se pueda, entonces, simular que la norma sigue vigente.

Ahora bien, basados en estas observaciones, nuestra hipótesis es que lo que tal vez distinga a los casos entre países con Estados más efectivos y órdenes sociales más estables, y otros con Estados fallidos y órdenes inestables son los niveles o grados de flagrancia con que se tolera la transgresión. El caso ruso, donde reconocidos jefes del crimen organizado realizan donaciones a las fuerzas de seguridad, vacacionan con los jefes policiales y tienen íntima amistad con ellos, hace evidente la articulación entre legalidad e ilegalidad. Algo similar sucede con las ferias o el juego clandestino en Argentina y Brasil, que también son de conocimiento público.

La diferencia con el caso de Estados Unidos no parece ser que la articulación entre lo legal y lo ilegal no exista, pero sí que no posee los mismos grados de flagrancia y visibilidad pública. Tanto las etnografías clásicas de las décadas de 1940 y 1950, como los casos que presenta Sanchez Jankowski muestran que en los barrios pobres de Estados Unidos ha existido y se mantiene la connivencia entre las bandas criminales y el sistema político; sin embargo, al menos en los actuales, hay un claro esfuerzo por disimular esos arreglos y ocultarlos de la luz pública. Así, a la vez que los casos revelan que la connivencia entre los agentes del Estado y las organizaciones criminales pueden darse en países desarrollados o en desarrollo, también sugieren 
que existen diferencias en cómo se produce y los grados de visibilidad que adquiere en uno y otro contexto.

\section{Conclusiones}

La intención de este texto, más cercano al ensayo que a un estudio sistemático o la demostración empírica, ha sido la de proponer algunos problemas complejos y articulados, más que proveer soluciones provisorias y parciales. No obstante, la validez del ejercicio se sostiene en que los problemas son relevantes al avance de la investigación sobre la manera en que se constituye el orden social a partir del vínculo entre legalidad e ilegalidad, y que la comparación entre los casos habilita algunas hipótesis y reflexiones productivas, aunque no alcancemos una respuesta definitiva.

Una primera cuestión ha sido llamar la atención sobre el hecho de que cuando se conceptualiza la articulación entre legalidad e ilegalidad se considera principalmente la casuística de los países en desarrollo, con regímenes democráticos más recientes o emergentes, y órdenes sociales más inestables. Esto introduce un supuesto tácito y problemático: que ese tipo de articulación no tiene lugar en países desarrollados con Estados efectivos. Sin embargo, aun exploraciones superficiales sobre la ilegalidad en este tipo de países sugieren que no hay una relación de externalidad absoluta entre legalidad e ilegalidad en esos contextos, solo que, en general, se han soslayado los vínculos a la hora de conceptualizar la forma en que se articulan el orden legal e ilegal en esos países. Claro que no se trata de negar que existan diferencias entre estos tipos de países, sino de evitar estereotipos que impiden conceptualizaciones más refinadas que aquellas que proponen contrastes absolutos.

Una segunda cuestión sobre la que intentamos llamar la atención es que el campo de estudios sobre la relación entre legalidad e ilegalidad permanece fragmentado. Lo que se observa, en general, es una acumulación casuística sobre la que existen pocos esfuerzos de síntesis. El campo parece proceder sobre la premisa de que cada caso presenta una situación excepcional o única, con un valor intrínseco e inherente que se perdería o alteraría si se lo ubicara en un marco comparativo con pretensiones generalizadoras. Es claro que esa premisa es buena para prevenir la tendencia a subordinar las particularidades de la casuística a modelos teóricos con sesgos socio o etnocéntricos, situación que ha afectado frecuentemente a las ciencias sociales, pero el desafío que enfrenta el campo es seguir eludiendo esa dificultad sin caer en el peligro alternativo de no divisar recurrencias allí donde las hay.

En este sentido, hemos sugerido que la actual casuística sobre la articulación entre legalidad e ilegalidad, que abarca muy diversos contextos regionales e his- 
tóricos, muestra algunas recurrencias que permitirían la construcción de una tipología. El caso de Rusia permite pensar hipótesis sobre prototipos posibles, que luego encontrarían variantes en América Latina o Norteamérica. Es evidente que el desarrollo de estos prototipos requeriría un análisis más extenso y una discusión más detallada, pero, pese al carácter ensayístico de este texto y lo precario o incompleto de las clasificaciones que proponemos, la comparación al menos sugiere posibles formas de llevarla a cabo, e hipótesis sobre algunas de las regularidades y diferencias principales.

Finalmente, una tercera cuestión-que en parte nos devuelve a la primera- es si el hecho de que existan interrelaciones entre legalidad e ilegalidad en sociedades con Estados efectivos y órdenes democráticos más estables hace que estas sean iguales o indistinguibles de lo que ocurre en Estados emergentes con democracias más recientes. La hipótesis que proponemos es que, si bien no hay diferencias absolutas, persisten desigualdades relativas y que es posible reconocerlas prestando atención a los niveles de flagrancia de la articulación entre legalidad e ilegalidad. Concretamente, lo que sugiere la casuística es que, en los países con Estados efectivos y sistemas democráticos más estables, aunque existe tolerancia a la articulación entre legalidad e ilegalidad esta es menor que en las sociedades en desarrollo con sistemas democráticos emergentes. El umbral que diferencia a unas de otras son los niveles de flagrancia que tienen esas articulaciones en uno y otro contexto. Es claro que los datos que presentamos tienen la capacidad de sugerir esta hipótesis, pero están lejos de comprobarla, razón por la cual este texto tiene más el propósito de abrir un debate que de clausurarlo.

\section{Referencias}

Albini, Joseph; Rogers, Robert; Shabalin, Victor; Kutushev, Valery; Moiseev, Vladimir; Anderson, Julie (1995). Russian Organized Crime: Its History, Structure and Function. Journal of Contemporary Criminal Justice, 11(4), 213-243.

Beliaev, Mariov; Sheptitskii, Anna (2012). Banditskaia Kazan. Kazan: Tatpoligraf.

Bendix, Reinhard (1979). Max Weber. Buenos Aires: Amorrortu.

Bourgois, Philippe (2011). En búsqueda de respeto. Buenos Aires: Siglo XXI.

Brinks, Daniel (2006). Inequality and the Rule of Law: Ineffective Rights in Latin American Democracies. En Informal Institutions and Democracy. Lessons from Latin America (pp. 134152), compilado por Gretchen Helmke; Steven Levitsky. Baltimore, MD: Johns Hopkins University Press. 
Cloward, Richard; Ohlin, Lloyd (1963). Delinquency and Opportunity. A Theory of Delinquent Gangs. Nueva York: The Free Press.

D’Andrade, Roy (1995). The Development of Cognitive Anthropology. Cambridge: Cambridge University Press.

Dent, Nicholas (2008). Rousseau. Londres: Routledge.

Desmond-Arias, Enrique; Barnes, Nicholas (2016). Plural Orders in Rio de Janeiro, Brazil. Current Sociology, 65(3), 448-465. https://doi.org/10.1177/0011392116667165

Dewey, Matias (2012). Illegal Police Protection and the Market of Stolen Vehicles in Buenos Aires. Journal of Latin American Studies, 44(4), 679-702.https://doi.org/10.107/0022216x12000831

Dewey, Matias (2015). El orden clandestino. Política, fuerzas de seguridad y mercados ilegales en Argentina. Buenos Aires: Katz.

Durkheim, Emile (1985). La división del trabajo social. Buenos Aires: Planeta Agostini.

Ferreira, I. A. (2017). Measuring state fragility: a review of the theoretical groundings of existing approaches. Third World Quarterly, 38(6), 1291-1309.

Galeotti, Mark (ed.). (2017). Russian and Post-Soviet Organized Crime. Londres: Routledge.

Gledhill, John (2018). Securitization, Mafias and Violence in Brazil and Mexico. Global Discourse, 8(1), 139-154. https://doi.org/10.1080/23269995.2017.1406679

Grimm, S., Lemay-Hébert, N., \& Nay, O. (2014). 'Fragile States': introducing a political concept. Third World Quarterly. 35(2), 197-209.

Gros, Jean-Germain (1996). Towards a Taxonomy of Failed States in the New World Order: Decaying Somalia, Liberia, Rwanda and Haiti. Third World Quarterly, 17(3), 455-471.

Helmke, Gretchen; Levitsky, Steven (2006). Introduction. En Informal Institutions and Democracy. Lessons from Latin America (pp.11-25), compilado por Gretchen Helmke; Steven Levitsky. Baltimore, MD: Johns Hopkins University Press.

Holzlehner, Tobias (2014). Shadow Networks: Border Economies, Informal Markets and Organized Crime in the Russian Far East. Zúrich: Instituto Max Planck.

Kukhianidze, Alexandre (2009). Corruption and Organized Crime in Georgia Before and After the "Rose Revolution". Central Asian Survey, 28(2), 215-234. https://doi. org/10.1080/02634930903043709

Kupatadze, Alexandre (2012). Organized Crime, Political Transitions and State Formation in Post-Soviet Eurasia. Londres: Palgrave Macmillan.

Malinowski, Bronislaw (1969). Crimen y costumbre en las sociedades salvajes. Barcelona: Ariel. 
Míguez, Daniel (2014). Cárceles y automóviles. Configuraciones del delito organizado en Argentina. En Estado y crimen organizado en América Latina (pp. 165-188), compilado por Daniel Míguez; Michel Misse; Alejandro Isla. Buenos Aires: Araucaria.

Misse, Michel (2014). Crimen, Estado y mercancías políticas en Brasil. En Estado y crimen organizado en América Latina (pp. 63-89), compilado por Daniel Míguez; Michel Misse; Alejandro Isla. Buenos Aires: Araucaria.

Misse, Michel (2018). Between Death Squads and Drug Dealers: Political Merchandise, Criminal Subjection and the Social Accumulation of Violence in Rio de Janeiro. The Global South, 12(2), 131-147. https://doi.org/10.2979/globalsouth.12.2.07

Moore, Barrington (1989). Los orígenes sociales de la dictadura y de la democracia. El Señor y el campesino en la formación del mundo moderno. Madrid: Península.

Nay, Olivier (2013). Fragile and Failed States: Critical Perspectives on Conceptual Hybrids. International Political Science Review, 34(3), 326-341. https://doi.org/10.1177/0192512113480054

O'Donnell, Guillermo (2002). Las poliarquías y la inefectividad de la ley en América Latina. En La (in)efectividad de la ley y la exclusión en América Latina (pp.305-336), compilado por Juan Méndez; Guillermo O’Donnell; Paulo Pinheiro. Barcelona: Paidós.

Pansters, Will (2018). Drug Trafficking, the Informal Order, and Caciques. Reflections on the Crime-Governance Nexus in Mexico. Global Crime, 19(3-4), 315-338.

Safarov, Anna (2012). Zakat Kazanskogo Fenomena : Istoriia Likvidatsii Organisovannykh Prestupnykh Formirovanii Tatarstana. Kazan: Tatarskoe Knizhnoe Izdatel'stvo.

Salagaev, Alexander; Shashkin, Alexande; Konnov, Alexey (2006). One Hand Washes Another: Informal Ties between Organized Criminal Groups and Law-Enforcement Agencies in Russia. Journal of Power Institutions in Post-Soviet Societies, 4(5), 1-22. https:// doi.org/10.400o/pipss.449

Sanchez-Jankowski, Martín (1991). Islands in the Street. Gangs and American Urban Society. Berkeley: University of California Press.

Savenije, Wim (2014) Enfrentando a las pandillas y al crimen organizado. Los militares en la seguridad pública en el Salvador, Guatemala y Honduras. En Estado y crimen organizado en América Latina (pp. 253-282), compilado por Daniel Míguez; Michel Misse; Alejandro Isla. Buenos Aires: Araucaria.

Shelley, Louise (1994). Post-Soviet Organized Crime. Demokratizatsiya, 2(3), 341-358.

Shelley, Louise; Scott, Erik; Latta, Anthony (eds.). (2007). Organized Crime and Corruption in Georgia. Londres: Routledge. 
Skinner, Quentin (1997) Reason and Rhetoric in the Philosophy of Hobbes. Cambridge: Cambridge University Press.

Sobering, Katherine; Auyero, Javier (2019). Collusion and Cynicism at the Urban Margins. Latin American Research Review, 54(1), 222-236. http://doi.org/10.25222/larr.370

Stephenson, Svetlana (2017). The Double Helix of Power: State and Private Violent Coalitions in Russia. Current Sociology, 65(2), 123-147.

Tilly, Charles (2006). Guerra y construcción del Estado como crimen organizado. Revista Académica de Relaciones Internacionales, 5, 1-26. Recuperado de https://revistas.uam.es/ relacionesinternacionales/article/view/4866

Vigil, James (2003). Barrio Gangs. Street Life and Identity in Southern California. Austin: University of Texas Press.

Weber, Max (1998). El político y el científico. Madrid: Alianza.

Wedel, Janine (2003). Clans, Cliques and Captured States: Rethinking "Transition" in Central and Eastern Europe and the former Soviet Union. Journal of International Development, $15(4), 427-440$.

Whyte, William (1943). Street Corner Society: The Social Structure of an Italian Slum. Chicago: Chicago University Press. 